\title{
reply
}

\section{How Common Are Fallacies?}

\author{
MARIE J. SECOR The Pennsylvania State University
}

In "Are Fallacies Common?" Gary Jason argues that fallacies occur frequently in the "ordinary contexts of argumentative persuasion,"1 and illustrates his point by analyzing the Nixon/ Kennedy and the Reagan/Mondale presidential campaign debates. He notes many instances of fallacy and emphasizes specific cases of ignoring the issue, false cause, and ad populem and ad hominem arguments. He concludes that the standard fallacies of logic texts are indeed common in ordinary arguments and that there is reason to continue teaching students to identify them. In response to this essay, I reexamine the examples Jason selects but suggest a different conclusion: that it is not at all clear that all these passages are fallacious and that to label them fallacious does little to help us understand either the discourse or the situation in which it occurs.

My argument has three parts. First, if we examine closely the fallacies of ignoring the issue, we might conclude not only that the candidates really do address the issues at hand, but that they often need to redefine those issues or explore their implications for their listeners. Although they do not always answer questions directly, there may be good reasons for their indirection. We need to understand what it means to ask and to answer questions in the context of presidential debate before we impute fallacy to the candidates' comments. Second, when we analyze the responses characterized as fallacies of false cause, it may be useful to distinguish between the way causal arguments are conducted within academic disciplines and the way they function in public political argumentation. And third, when we identify an ad populem or ad hominem fallacy, we also need to ask what it means to condemn or condone the use of such techniques. My general point is that the very term fallacy can be regarded as what Jeremy Bentham would call a question-begging epithet. It carries with it disciplinary assumptions that privilege the evaluative function of logic but are of less help in understanding and assessing discourse in other fields, especially rhetorical discourse addressed to a nonspecialist public contemplating a specific choice at the polls.

Let us begin with the imputed fallacies of ignoring the issue. I will quote in full each of the passages from the Jason article and follow with my own commentary. The first passage is Nixon's reply to the question of whether $\mathrm{U}-2$ flights should have been conducted during Khrushchev's visit to the United States:

Mr. Nixon: Now, looking to the U-2 flights, I would like to point out that I have been supporting the President's position throughout. I think the President was correct in ordering these flights. I think the President was correct, certainly, in his decision to continue the flights while the conference was going on. I noted, for example, in reading a particular discussion that Senator Kennedy had with Dave Garroway 
shortly after the uh - his statement about regrets, that uh - he made the statement that he felt that these particular flights were ones that shouldn't have occurred right at that time, and the indication was how would Mr. Khrushchev have felt if we had had a flight over the United States while he was visiting here. And the answer, of course, is that Communist espionage goes on all the time. The answer is that the United States can't afford to have an espionage lack - or should I say an intelligence lag - any more than we can afford to have a missile lag.

Jason accuses Nixon of addressing a different issue, but actually he does first answer the question directly: he says, "I think the President was correct, certainly, in his decision to continue the flights." He then offers what Stephen Toulmin might call a warrant, or inference-license, to support his claim: because "Communist espionage goes on all the time" and the US cannot afford to lag in espionage. In other words, the president's policy was correct because it falls under the general policy of continued espionage on both sides. Kennedy's response to the same question can be seen not as a rebuttal of Nixon's evasion but as a laying out of a slightly different argument, with a significant qualification attached to the warrant:

Mr. Kennedy: Number two, on the question of the U-2 flights. I thought the U-2 flights in May just before the conference was a mistake in timing because of the hazards involved, if the summit conference had any hope for success. I never criticized the U-2 flights in general, however. I never suggested espionage should stop. It still goes on, I would assume, on both sides.

Kennedy in effect argues that the president's decision was wrong. He concedes the general warrant that Nixon articulated (that espionage goes on all the time), but he qualifies it by identifying the exceptional circumstance of the summit as a diplomatic occasion when it would be tactless to pursue the general policy - or at least this one risky manifestation of that policy. Although the two candidates certainly disagree in their evaluation of the president's policy, they do not ignore the issue.

In the next exchange, McGee asks Nixon two questions, whether new laws are needed "to protect the public against excessive use of power by labor unions" and what such laws would do:

\begin{abstract}
Mr. Nixon: Mr. McGee, I am planning a speech on that subject next week. Also, so that we can get the opportunity for the questioners to question me, it will be before the next television debate. I will say simply, in advance of it, that I believe that in this area, the laws which should be passed, as far as the big national emergency strikes are concerned, are ones that will give the president more weapons with which to deal with those strikes. Now, I have a basic disagreement with Senator Kennedy, though, on this point. He has taken the position, when he first indicated in October of last year, that he would even favor compulsory arbitration as one of the weapons the president might have to stop a national emergency strike. I understand in his last speech before the Steelworkers Union, that he changed that position and indicated that he felt that government seizure might be the best way to stop a strike which could not be settled by collective bargaining. I do not believe we should have either compulsory arbitration or seizure. I think the moment that you give to the union, on the one side, and to management, on the other side, the escape hatch of eventually going to government to get it settled, that most of these great strikes will end up being settled by government, and that will be in the end, in my opinion, wage control; it would mean price control - all the things that we do not want. I do believe, however, that we can give to the president of the United States powers, in addition to what he presently has in the factfinding area, which would enable him to be more effective than we have been in handling these strikes.
\end{abstract}

Jason claims that Nixon "does not answer the question whether he would propose new laws to restrict the power of unions, and if so, which ones." But Nixon does answer the question quite directly, if not as specifically as we might wish: he says that laws should be passed giving "the president more weapons with which to deal with these strikes." Nixon then goes on to reject two specific kinds of laws he claims are advocated by Kennedy: those favoring compulsory arbitration and those allowing for govern- 
ment seizure. In referring to his forthcoming speech Nixon might be criticized for being unspecific but not, I think, for being irrelevant. If the public can be protected from excessive union power either by directly restricting the unions or by increasing presidential power to intervene, Nixon clearly advocates the latter course of action. It may, of course, be in his political interest to withhold details until a future speech, but he is not really guilty of ignoring the issue.

In the following exchange, Kennedy is asked whether he considers the twenty-seven and a half per cent oil depletion allowance inequitable and whether he would ask that it be cut:

\begin{abstract}
Mr. Kennedy: Mr. McGee, there are about a hundred and four commodities that have some kind of depletion allowance - different kinds of minerals, including oil. I believe all of those should be gone over in detail to make sure that no one is getting a tax break; to make sure that no one is getting away from paying the taxes he ought to pay. That includes oil; it includes all kinds of minerals; it includes everything within the range of taxation. We want to be sure it's fair and equitable. It includes oil abroad. Perhaps that oil abroad should be treated differently than the oil here at home. Now the oil industry recently has had hard times. Particularly some of the smaller producers. They're moving about eight or nine days in Texas. But I can assure you that if I'm elected president, the whole spectrum of taxes will be gone through carefully, and if there is any inequities in oil or any other commodity, then I would vote to close that loophole. I have voted in the past to reduce the depletion allowance for the largest producers; for those from five million dollars down, to maintain it at twenty-seven and a half percent. I believe we should study this and other allowances; tax expense, dividend expenses and all the rest, and make a determination of how we can stimulate growth; how we can provide the revenues needed to move our country forward.
\end{abstract}

Jason comments that Kennedy "never specifically answered the questions." I would argue that although he says a great deal besides answering the questions, he does answer them. Kennedy says that in the past he voted to maintain the twenty-seven and a half percent allowance for smaller producers; we must therefore assume that he thought the allowance fair and reasonable at the time. Political wisdom being subject to change and development, he says that we "should continue to study this and other allowances." That is, he makes no guarantee that he would continue to support this specific tax provision in the future. The answer may be equivocal, but it is not an ascent to generality that ignores the issue at hand. The questions, in this case and many others, are complex and often loaded, and the candidates need to answer them carefully. It would be misleading as well as politically imprudent for Kennedy to call the allowance unfair, especially when he voted for it, or fair, if he might withdraw his approval in the future.

Turning to the Reagan/Mondale debate, we can see even more clearly how loaded some of the questions are:

Q. Mr. Mondale, two related questions on the crucial issue of Central America. You and the Democratic Party have said that the only policy toward the horrendous civil wars in Central America should be on the economic developments and negotiations with, perhaps, a quarantine of Marxist Nicaragua. Do you believe that these answers would in any way solve the bitter conflicts there? Do you really believe that there is no need to resort to force at all? Are not these solutions to Central America's gnawing problems simply again too weak and to late?

Mondale's response to this very loaded and complex question is not so much an evasion of it as an attempt to describe his policy more accurately than the questioner did:

Mondale: I believe that the question oversimplifies the difficulties of what we must do in Central America. Our objectives ought to be to strengthen the democracy, to stop Communist and other extremist influences and stabilize the community in that area.

To do that, we need a three-pronged attack. One is military assistance to our friends who are being pressured. Secondly, a strong and sophisticated economic aid program and human rights program that offers a better life and a sharper alternative to the alternative offered by the totalitarians who oppose us. And finally, a strong diplomatic ef- 
fort that pursues the possibilities of peace in the area.

When the question is broadened and repeated, Mondale again tries to refine it:

Q. Mr. Mondale, if ! could broaden the question just a little bit. Since World War II, every conflict that we as Americans have been involved with has been in nonconventional or irregular terms and yet we keep fighting in conventional or traditional military terms. The Central American wars are very much in the same pattern as China, as Lebanon, as Iran, as Cuba in the early days. Do you see any possibility that we are going to realize the change in warfare in our time or react to it in those terms?

Mondale: We absolutely must, which is why I responded to your first question the way I did. It's much more complex. You must understand the region, you must understand the politics in the area, you must provide a strong alternative, and you must show strength - and all at the same time. That's why I object to the covert action in Nicaragua. That's a classic example of a strategy that's embarrassed us, strengthened our opposition and undermined the moral authority of our people and our country in the region.

Jason accuses Mondale of ignoring the issue (how the US should handle unconventional wars) by speaking in "glittering generalities." Actually, however, Mondale is not general but specific in identifying a strategy (covert action in Nicaragua) that has not worked in an unconventional situation; his point is that the way we have so far responded to unconventional situations has been very ineffective. If this exchange shows anything, it illustrates more how questions can be misleading and inaccurate than how the responses ignore them. It would not be reasonable to expect a direct response to questions that misrepresent one's position.

In the next exchange, Reagan is asked about how the United States would handle friendly dictators:

Q. Mr. President, I want to ask you about negotiating with friends. You severely criticized President Carter for helping to undermine two friendly dictators who got into trouble with their own people, the Shah of Iran and President Somoza of Nicaragua. Now there are other such leaders heading for trouble, including President Pinochet of Chile and President Marcos of the Philippines. What should you do and what can you do to prevent the Philippines from becoming another Nicaragua?

Reagan: Morton, I did criticize the President because of our undercutting of what was a stalwart ally, the Shah of Iran. And I am not at all convinced that he was that far out of line with his people or that they wanted that to happen.

The Shah had done our bidding and carried our load in the Middle East for quite some time and I did think that it was a blot on our record that we let him down. Had things gotten better, the Shah, whatever he might have done, was building low-cost housing, had taken land away from the mullahs and was distributing it to the peasants so they could be land-owners, things of that kind. But we turned it over to a maniacal fanatic who has slaughtered thousands and thousands of people calling it executions.

The matter of Somoza, no, I never defended Somoza. And as a matter of fact, the previous Administration stood by and so did I - not that I could have done anything in my position at that time. But for this revolution to take place and the promise of the revolution was democracy, human rights, free labour unions, free press. And then just as Castro had done in Cuba, the Sandinistas ousted the other parties to the revolution. Many of them are now the Contras. They exiled some, they jailed some, they murdered some. And they installed a Marxist-Leninist totalitarian Government.

And what I have to say about this is, many times - and this has to do with the Philippines also - I know there are things there in the Philippines that do not look good to us from the standpoint right now of democratic rights. But what is the alternative? It is a large Communist movement to take over the Philippines.

They have been our friend for - since their inception as a nation. And I think that we've had enough of a record of letting, under the guise of revolution, someone that we thought was a little more right than we would be, letting that person go and then winding up with totalitarianism pure and simple as the alternative and I think that we're better off, for example, with the Philippines of trying to retain our friendship and help them right the wrongs we see rather than throwing them to the wolves and then facing a Communist power in the Pacific.

Again the candidate is accused of ig- 
noring the issue of how to prevent the Philippines from becoming another Nicaragua. But although he takes a while to get to the point, he does not ignore it. He uses two analogies, if I may summarize his argument: we withdrew support from the Shah, and a worse regime followed; we let Somoza fall, and the Sandinistas took over; we should, in his view, support Marcos, try to retain our friendship, and help right the wrongs we see rather than desert him and face a Communist power in the Pacific. I suppose Reagan might have been more specific about the form such support and help would take, but these are easy enough to imagine: our friendship is usually manifest in financial support and defined conditions for its continuation. And, of course, we might debate the assumption that a Communist takeover is the alternative to Marcos. But Reagan is not really guilty of ignoring the issue.

In his concluding remarks to this section, Jason raises several important points, which, in combination, undermine his argument that fallacies are common. First, he defines fallacy as "an error in argumentation but not necessarily a dishonest or deliberate one." His purpose here seems to be charitable: to remove the intention of the author as the locus of fallacy makes it an accusation not of moral failing but simply of error. But even error must be assessed from some point of view in relation to some sense of purpose shared by analyst and audience. When, as in ignoring the issue, the imputed error does not reside in the form of a syllogism, it must be assessed from some perspective shared by analyst and reader. But Jason's second comment steps down from the vantage point of the analyst and concedes that candidates engaged in debate are prisoners of a format. They are constrained by the time, the situation, the quality of the questions, and the need to at least appear to give an answer. This is a very significant and humane concession, and it strikes at the heart of his imputation of fallacy. It does not help to shift the blame from the politicians, who in some sense, cannot be blamed for the logical lapses they have been accused of, to the audience, who are forced to decide on the basis of inadequate performances and are themselves, we must conclude, no less prisoners of the debate format in their role as listeners. If blame is not the issue for the politicians, it should not be the issue for the audience, who has even less control over the rhetorical situation.

Finally, Jason ends this section of his article by wishing that we had some way of allowing candidates to grapple with complex issues. Once again, we must all agree, but the observation seriously undercuts the accusation of fallacy. We are left to lament that the debate situation is flawed and does not permit the kinds of answers we could respect, that the candidates are not to be accused of stupidity or ill will, and that in a better world people could answer questions and present their positions more fully and convincingly. It seems then that error in argumentation should be assessed only if we assume ideal conditions for argument.

My own analyses, admittedly charitable, have tried to show how, all things considered, the candidates tried to answer questions that were too broad, too narrow, too loaded, or too complex. Sometimes they seemed rushed in their answers, and at other times they seemed to be elaborating short answers to fill an allotted time. They did so by being general rather than specific or by being specific rather than general, by exploring the implications of their answers or the assumptions behind them, by reminding questioners of the temporal, changing nature of politics, by exploring analogies. In short, they used all the various kinds of argument at their disposal to get at the broader meanings of the questions, meanings that could not be addressed by direct, simple responses. We are left to conclude that an ideal situation, where questions are clear and answers straightforward, is the 
only one in which fallacy could be avoided. But of course such situations do not exist, so it is hard to see what end is served by calling fallacious the attempts of the candidates to do what they could with the questions in the time they were given to answer them.

Jason's analysis moves onto more solid ground when he takes up examples of false cause. Where in the ignoring the issue section, I felt I could see how the candidates were really attempting to address the issue, here their responses seem more open to criticism, even by the casual reader. The following passages show how Nixon dissociates the Republican party with war (and by implication associates the Democratic party with it) and associates himself with the Republican administration that is credited for the decrease in man-hours lost by strikes, while Kennedy implies that the Republicans are to blame for increased agricultural spending.

Mr. Nixon: Yes. As a matter of fact, the statement that Senator Kennedy made was that - to the effect that there were trigger-happy Republicans, that my stand on Quemoy and Matsu was an indication of trigger-happy Republicans. I resent that comment. I resent it because it's an implication that Republicans have been trigger-happy and, therefore, would lead this nation into war, I would remind Senator Kennedy of the past fifty years. I would ask him to name one Republican president who led us into war. I do not mean by that that one party is a war party and the other party is a peace party. But I do say that any statement to the effect that the Republican party is trigger-happy is belied by the record.

Mr. Nixon. One last point I should make. The record in handling strikes has been very good during this Administration. We have had less manhours lost by strikes in these last seven years than we had in the previous seven years, by a great deal. And I only want to say that however good the record is, it's got to be better. Because in this critical period of the sixties we've got to move forward, all Americans must move forward together, and we have to get the greatest cooperation possible between labour and management. We cannot afford stoppages of massive effect on the economy when we're in the terrible competition we're in with the Soviets.
Mr. Kennedy. On the question of the cost of our budget, I have stated that it's my best judgment that our agricultural program will cost a billion and a half, possibly two billion dollars less than the present agricultural program. My judgment is that the program the Vice President put forward, which is an extension of Mr. Benson's program, will cost a billion dollars more than the present program, which costs about six billion dollars a year, the most expensive in history. We've spent more money on agriculture in the last eight years than the hundred years of the Agricultural Department before that.

In each case, Jason points out the unfairness of the association: just because wars occur during an administration does not mean they are a war party; the amount of strike activity has little to do with which political party is in power; and presidents do not have line-item veto that would enable them to control spending on specific programs. Certainly the arguments of Kennedy and Nixon are commonplaces of political discourse: the party in power takes responsibility for all good things that happen and points to "other factors" outside anyone's control to explain all the bad things. Conversely, the other party is held responsible for all the bad things that happen in its administration, and all good things are attributable to more complex causes (or they have unforeseen bad consequences that will later ensue). Such common political stances certainly look like examples of false cause, or at least of an inadequate causal model.

But once again, we might ask "false" or "inadequate" from what point of view? We all know that military strategists, economists, and historians make very elaborate causal arguments, constructing intricate models that take whole books to explain, work out, and verify. But the voter's perspective is not the same as the scholar's. It is reasonable to expect that there be some difference between arguing for causes in the forums of scholarly disciplines, where one's causal model must be very precise and anticipate the efforts of other scholars to refute it, and arguing for 
causes in the public forum of presidential debate, where notions of responsibility are much more diffuse. As Aristotle says, we can only ask of a subject the degree of precision that is appropriate to it. Politicians are not economists, and voters act on causal assumptions different from those of scholars. Thus fallacies of false cause in the statements of the candidates may be obvious from the vantage of the academic critic, whose standard of evidence for causality may be very high, but such analysis tells us little about the way voters make or even should make decisions. Perhaps that is just another way of saying that the rhetorical context of political discourse differs from that of scholarly discourse.

The section on the ad populum and ad hominem fallacies raises a third concern: that of the problem of calling such phenomena fallacies at all. After pointing out several attempts of candidates to associate themselves with popular values and figures, Jason notes that the closing statements in the Reagan/Mondale debate brought out strong ad populum appeals.

Mr. Mondale: I want this nation to protect its air, its water, its land and its public health. America is not temporary. We're forever. And as Americans, our generation should protect this wonderful land for our children.

I want a nation of fairness, where no one is denied the fullness of life or discriminated against, and we deal compassionately with those in our midst who are in trouble.

And above all, I want a nation that's strong. Since we debated two weeks ago, the United States and the Soviet Union have built 100 more warheads, enough to kill millions of Americans and millions of Soviet citizens.

Mr. Reagan: We shouldn't be dwelling on the past or even the present. The meaning of this election is the future, and whether we're going to grow and provide the jobs and the opportunities for all Americans and what they need. Several years ago I was given an assignment to write a letter. It was to go into a time capsule and would be read in 100 years when that time capsule was opened. I remember driving down the California coast one day. My mind was full of what I was going to put in that letter about the problems and the issues that confront us in our time and what we did about them, but I couldn't completely neglect the beauty around me - the Pacific out there on one side of the highway shining in the sunlight, the mountains of the coast range rising on the other side, and I found myself wondering what it would be like for someone, wondering if someone 100 years from now would be driving down that highway and if they would see the same thing.

It is not surprising that both candidates make broad popular appeals in their speeches. Closing statements, even in debates, function as perorations, and can quite reasonably be expected to unite (or try to unite) the candidates and their audiences in a celebration of shared values. Jason seems to be aware of this practise, and he points out that it is not only deceitful politicians who use ad populum appeals: "no, even very decent politicians engage in such rhetoric." Then he advises readers that such appeals should be recognized as fallacies "even if we condone (my emphasis) their usage in contexts such as the one under consideration." If we condone rather than condemn the use of such tactics, what is the use of talking about the ad populum as a fallacy? If fallacies are not the product of deceitful intent, as we saw earlier, and if they are used by quite decent politicians, and if we can even condone their usage in the context of debate, there seems to be little reason to consider them errors. They are errors only if we hold political discourse to a purely rational ideal according to which candidates are asked perfectly straight-forward questions which they are expected to answer without any tint of emotion or bias toward their own candidacy.

Admittedly, the ad populum and the ad hominem are particularly risky tactics for politicians because they can offend listeners who find the associations farfetched or unconvincing or unnecessary to reinforce commitment made on other grounds. The greater the strain on the audience's sense of connectedness, the more dangerous the appeal. It may even 
be said that such techniques pander to the crudest public taste and that more rational audiences will inevitably find them offensive because they will accept such connections as reasonable. Although the candidates are talking to audiences who differ in reasonableness, I think we would agree that it is a good idea to treat audiences "as if" they were more rather than less reasonable. perhaps that is as close as we can come in political discourse to Perelman's universal audience as an ideal of rationality. ${ }^{2}$ But it would be illusory to judge political debates from the perspective of a purely rational evaluator who assumes that questions are clear and that they have clear answers, that causal associations must always be carefully argued into place, and that emotional appeals to shared values have no place in political discourse.

While it may be true that the "traditional categories of logical error" have been "discerned by scholars of many different cultures over millenia," the statement suggests the limitation of the approach: what scholars perceive as error presupposes a culturally universal rational ideal that they define. Whether or not such an ideal is desirable or feasible, there is little reason to suppose that any political debate should be held to it. So while we can still identify fallacies and teach students to do the same, to do so may be to imply an unrealistically superior and judgmental attitude toward ordinary discourse.

Of course, the alternative might be seen as even more undesirable. If we don't privilege a culturally universal rational ideal, from what standpoint can we criticize any argument as inadequate or unfair? It might be argued that it is preferable to adhere to an infrequently reached standard than to none at all. Questions like these have divided philosophers and rhetoricians for centuries, perhaps millenia, and I cannot hope to resolve them here. I would only invoke Stephen Toulmin's suggestion that arguments in different fields should be evaluated differently, that we test "our ideas against our actual practice of argument-assessment, rather than against a philosopher's ideal. ${ }^{\prime \prime 3}$ That's a rhetorician's perspective, although public argumentation, like that found in presidential debate, has not usually been considered a field in the same way that academic disciplines are. Still, such arguments are addressed to audiences with very specific interests and very specific practical purposes, and we should be able to identify standards that take account of the contexts and peculiar forums of presidential debate. If I were pushed to suggest what such appropriate standards might be, I would suggest, minimally, that candidates should try to raise rather than lower the level of public discourse, to make the public more rather than less aware of complexity in the political process. Such a standard might represent an ideal of rationality, but not an absolute one. Perhaps other analysts can offer more.

\section{Notes}

1 Gary Jason, "Are Fallacies Common: A Look at Two Debates," Informal Logic, 8:2 (Spring 1987), 81-92. All other references to Jason and to the passages from the debates are to this article.

2 Chaim Perelman and L. OlbrechtsTyteca. The New Rhetoric. (Notre Dame: Notre Dame University Press, 1969), 31-35.

3 Stephen Toulmin. The Uses of Argument. (Cambridge: Cambridge University Press, 1958), 10.

Professor Marie J. Secor, Department of English, Pennsylvania State University, 117 Burrowes Building, University Park, Pennsylvania 16802. 